INVESTIGACIÓN

\title{
CARTILLA CERRANDO BRECHAS, UNA ALTERNATIVA PARA LA CONSTRUCCIÓN DE COMUNIDAD A PARTIR DEL LIDERAZGO COMUNAL
}

\section{BOOK CLOSING GAPS, AN ALTERNATIVE TO BUILD COMMUNITY LEADERSHIP FROM THE COMMUNITY}

\author{
MSc. Eduardo Sánchez Navarro ${ }^{\mathrm{a}}$ \\ ${ }^{a}$ Universidad Francisco de Paula Santander Ocaña, Grupo de Investigación GIFEAH, Vía \\ Acolsure Sede el Algodonal, Ocaña - Norte de Santander, Colombia, esanchezn@ufpso.edu.co
}

Fecha de recepción: 10-12-2015

Fecha de aprobación: 03-04-2016

Resumen: El desarrollo de las comunidades en tiempos modernos, obedece a una necesidad real y latente, en la que se hace necesario que gobiernos, instituciones públicas y privadas encaminen esfuerzos al desarrollo de políticas y programas para el fortalecimiento de las estructuras sociales que permitan un desarrollo sostenible al interior de las comunidades.

De esta manera la Cartilla cerrando brechas, resume todo un trabajo exploratorio, de observación y evaluación del estado actual de las juntas de acción comunal en la ciudad de Ocaña, norte de Santander, a fin de construir un manual instructivo y didáctico que les permitiera a los líderes comunales tener una orientación clara y precisa de su rol y función dentro de sus comunidades. Y es que a través de los fundamentos que sustentan la existencia de un estado social de derecho, como lo profesa nuestro país a través de la constitución de 1991, en donde se concibe el desarrollo integral de todo individuo en medio de una sociedad activa y participativa que posibilite una verdadera democracia incluyente.

Palabras clave: Inclusión y exclusión social, liderazgo comunitario, Participación ciudadana y políticas públicas.

Abstract: The development of the communities in modern times obeys a latent and real need, where it is necessary for governments, public and private institutions lead efforts to the development of policies and programs for the strengthening of the social structures that allow a sustainable development within the communities. In this way the primer "Cerrando Brechas (Closing Gashes) summarizes all exploratory work, observation and evaluation of the community action councils in the city of Ocaña, Norte de Santander. In order to build an instructive and didactic manual that would allow community leaders to have an orientation clear and precise role and function within their communities. And through the foundations supporting the existence of a social state of law, as professes our country through the Constitution of 1991, where is 
conceived the development of every individual in the middle of an active and participatory society that makes possible a real inclusive democracy.

Key words: Inclusion and social exclusion - community leadership - civil Participation and public politics.

\section{INTRODUCCIÓN}

En Colombia existen cerca de 50.000 Juntas de Acción Comunal, ellas hacen presencia barrios y veredas de todos los municipios, de todos los estratos y de las distintas clases sociales. Este es el tejido de organizaciones comunitarias con mayor cobertura que hay en el país. Son parte de una estructura nacional denominada organismos de acción comunal que tiene el objeto de promover el desarrollo social y de hacer valer los derechos de los vecinos asociados a ellas.

A las Juntas de Acción Comunal se les atribuyen dos contribuciones importantes al proceso de modernización de la sociedad colombiana: el control y ordenamiento de los procesos de urbanización y la reconstrucción del tejido social rural después de la violencia bipartidista de los años 50 y 60 del siglo pasado. Si no fuera por la red de organizaciones de vecinos que se conformó como respuesta a los problemas de servicio e infraestructura, el caos en el crecimiento de las ciudades habría sido peor. Pero, también, si no fuera por la integración social que promovieron las Juntas de Acción Comunal a los vecinos del sector rural, las posibilidades de entendimiento entre estos no hubiese sido posible y las secuelas de la violencia partidista de los años 50 del siglo pasado no se habrían superado.

La acción de las juntas comunales también ha trascendido a los espacios de deliberación y decisión pública. Han sido actores fundamentales de la implantación de los principios constitucionales de 1991 y en definición de los contenidos de los planes de desarrollo y ordenamiento territorial. De igual manera su incidencia en las iniciativas productivas, a través de formas solidarias de producción, distribución y consumo, la convierten en una opción a los problemas de pobreza y exclusión social.

No obstante este propósito social de la juntas se ha desvirtuado al pasar de los años, es evidente como las representaciones sociales han hecho de acción popular y democrática en un negocio en donde priman intereses particulares por encima de los colectivos.

Este proyecto desarrollo una investigación exhaustiva a fin de determinar el estado real de las estructuras de las juntas de acción comunal de Ocaña en su área urbana.

El propósito final fue producir un manual instructivo, con una redacción simple, clara y fácil de entender, abordando temas que son de suma importancia para los dignatarios, así como también la explicación de conceptos propios de su rol y consejos para ser un buen líder.

\section{METODOLOGÍA}

Este proyecto tuvo por objetivo producir una cartilla o manual instructivo destinado a la orientación y formación de los líderes comunales. 
Se utilizó la investigación-acción como método de investigación, que fue desarrollado en cinco etapas: elección del contenido, con base en las necesidades de los presidentes de juntas de acción comunal; creación de las ilustraciones; preparación del contenido basado en la literatura científica; y validación del material por expertos y la sociedad civil.

El trabajo resultó en la producción de la versión final del material en formato de cartilla, que tuvo el título de "Cerrando Brechas".

La participación activa de los profesionales y de los dignatarios, usando una estrategia dialógica y colectiva, impregnó el proceso de construcción de la cartilla. Las opiniones de los líderes y de los expertos, que consideraron la cartilla enriquecedora y esclarecedora, justifican el uso de la cartilla como un recurso adicional de las actividades educativas realizadas durante el ejercicio como líderes en las diferentes comunidades.

\section{Método de la investigación}

El método de la investigación-acción fue seguido durante todo el proceso de desarrollo de la cartilla. El principal presupuesto de este método es la construcción del conocimiento de manera colectiva y participativa, buscando identificar soluciones para un problema que necesita ser estudiado. La solución encontrada puede producir reflejos positivos para las personas, la comunidad y la sociedad. (1)

Este proceso fue compuesto por cinco fases

(Figura 1), conducido en el período entre febrero de 2015 y diciembre de 2015.

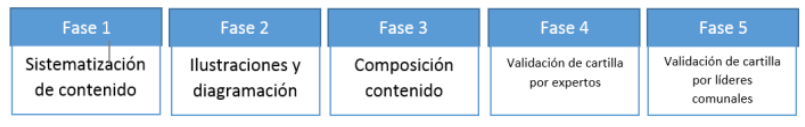

Figura 1. El Proceso de producción cartilla

La primera fase fue basada en las necesidades de los líderes comunales y de las comunidades. Estos datos fueron obtenidos cuando el investigador condujo seis reuniones, una por comuna. $\mathrm{La}$ recolección de datos preliminar se realizó en el Centro de convivencia ciudadana. Los líderes comunales fueron invitados a través de la oficina de desarrollo social de la alcaldía municipal de Ocaña a participar en el grupo. En la primera reunión, se solicitó a los participantes expresar sus dudas y necesidades educacionales, así como sus preferencias en relación a la forma de conducir las reuniones. Al final de las reuniones, los participantes evaluaban los contenidos abordados y los métodos educativos utilizados en la reunión anterior.

El uso de estos recursos permitió la identificación de las expectativas de los propios participantes y promovió la contribución activa en la elaboración de los contenidos y la elección de estrategias a ser utilizadas en la reunión siguiente.

Todas las reuniones fueron registradas y transcritas literalmente. Estos datos fueron utilizados para orientar la elaboración de los tópicos de la cartilla y de sus contenidos principales.

La elaboración del contenido fue basada en la literatura científica, para garantizar que fuese fidedigno. Algunas informaciones relacionadas a servicios públicos disponibles para los líderes comunales fueron incluidas en la cartilla y la exactitud de estos datos fue confirmada por teléfono o email. 
En la segunda fase, libros e imágenes de internet fueron tenidos en cuenta para encontrar las mejores ilustraciones y de esta manera tenerlas en cuenta para su posterior vectorización. Las imágenes didácticas fueron seleccionadas y usadas como base para la elaboración de las ilustraciones por un profesional especializado.

En la tercera fase, el contenido preliminar fue desarrollado con mucha atención debido a que la información fue considerada esencial. Este contenido fue sometido al trabajo de edición y diagramación. El desarrollo de esta fase fue basado en el criterio establecido previamente para todo el proceso de construcción de la cartilla, esto es, facilidad de lectura y claridad de contenido.

La primera versión de la cartilla fue sometida a la evaluación de expertos, los que validaron la cartilla. Los criterios adoptados para la inclusión de los profesionales de la salud, sociología, derecho, trabajadores sociales y comunicadores sociales como expertos fueron: trabajar en políticas públicas y desarrollo social, tener experiencia anterior en actividades de promoción de proyectos de intervención social, y tener experiencia relacionada a la validación de materiales educativos y didácticos.

A los representantes de consejos de clase profesional, gerentes de organizaciones y de servicios de salud se les solicitó indicar profesionales para participar del proceso de validación de la cartilla.

En esta cuarta fase, un cuestionario fue utilizado para el proceso de validación. Las preguntas estuvieron relacionadas a la adecuación de las informaciones, lenguaje e ilustraciones.
Para cada fase de la cartilla, los profesionales evaluaron la adecuación y la presentación de las informaciones, considerando la perspectiva de los lectores.

En relación al lenguaje, ellos evaluaron la conveniencia y la facilidad de comprensión y si los conceptos más importantes fueron abordados con un vocabulario claro y objetivo; ellos también indicaron posibles errores conceptuales.

En relación a las ilustraciones, los profesionales evaluaron la adecuación de la composición visual, la atracción que ejercía y la organización, así como la cantidad y la adecuación de las ilustraciones.

Al final de la validación, fue solicitado ofrecer una opinión general sobre la cartilla; sus recomendaciones fueron integralmente aceptadas e incorporadas. Posteriormente, la nueva versión de la cartilla fue sometida a otro proceso de edición, revisión y diagramación.

En la quinta fase, los dignatarios fueron convocados a participar del estudio en cuanto esperaban por la oficina de desarrollo social de la alcaldía municipal de Ocaña. Los criterios adoptados para la inclusión de las líderes comunales fueron: estar en acompañamiento del municipio, y ser alfabetizados, esto es, saber leer y escribir. Se solicitó que leyesen la cartilla y analizasen en términos de entendimiento del vocabulario, así como la adecuación de las ilustraciones. También fue solicitado indicar los términos extraños o difíciles y sugerir términos para sustituirlos por otros que considerasen fáciles y comprensibles.

El proceso de validación realizado por expertos y por líderes comunales y fue conducido hasta alcanzar la ausencia de nuevas recomendaciones para cambios. Este criterio fue fundamental para 
determinar la cantidad de líderes comunales incluidos en este estudio.

El proyecto de investigación fue aprobado por el Comité de Investigación y todos los participantes aprobaron el producto. Finalmente se llevó a cabo la ceremonia de certificación y entrega de materia (Cartilla cerrando Brechas) el día 14 de diciembre de 2015 en la plazoleta de san Francisco de Ocaña, Norte de Santander.

\section{RESULTADOS}

En este estudio participaron 62 colaboradores, siendo 5 profesionales y 53 dignatarios. Los profesionales fueron un abogado, un trabajador social, un psicólogo, un sociólogo y un comunicador social. Tres de ellos tenían el título de especialista, uno maestría y el otro pregrado.

Las ocupaciones de estos líderes comunales eran: amas de casa (13), trabajadores independientes (14), comerciantes (14) estudiantes (9) empleados contratados (3). Una gestante estaba desempleada.

La escolaridad varió entre el primer grado y la enseñanza superior. Todas residentes de Ocaña, con edades de entre 19 a 73 años de edad.

La primera versión de la cartilla tenía 30 páginas; fue impresa en blanco y negro y el título era "Cerrando brechas" Manual instructivo de formación y capacitación para los dignatarios de las juntas de acción comunal. Este título fue mantenido hasta la versión final de la cartilla.

En el proceso de validación, los expertos ofrecieron sugerencias relacionadas a la información, al lenguaje y al vocabulario. Además, estos sugirieron la reformulación y la exclusión de informaciones, además de la reformulación de las ilustraciones y del vocabulario.

Todos los expertos hicieron una evaluación positiva de la cartilla. El lenguaje fue considerado fácil para el entendimiento y este aspecto fue destacado como vital para promover el interés de los presidentes de juntas de acción comunal.

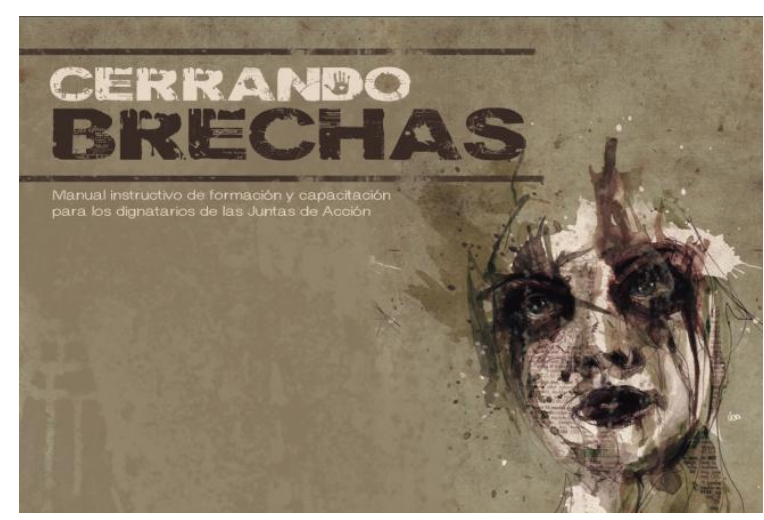

Figura 2. Portada Cartilla Cerrando Brechas

\section{CONCLUSIONES}

La principal propuesta de la creación de esta cartilla fue ampliar el potencial de los dignatarios de juntas de acción comunal de Ocaña y de sus comunidades y promover la condición de sus barrios.

La cartilla es un soporte para los profesionales y las personas interesadas en ejercer representaciones a nivel social para la promoción de desarrollo, para que superen dudas y dificultades que guíen el proceso de liderazgo y participación ciudadana.

La versión online de esta cartilla estará disponible para el público en el site de la Universidad. Esto representa un importante paso para el acceso de los lectores, pero no es suficiente para representar un recurso ampliamente utilizado por los usuarios de 
este proyecto. Siendo necesario colocarla a disposición en la versión impresa para las instituciones públicas.

Se destaca que la cartilla reposa en su versión impresa con 100 ejemplares en la oficina de desarrollo social de la alcaldía municipal de Ocaña, así como también fue entregada a los líderes que participaron en el proceso con una calidad extraordinaria a full color y en propalcote para una larga vida.

\section{FINANCIACIÓN}

Este proyecto fue posible gracias al respaldo académico y financiero que dio la Universidad Francisco de Paula Santander Ocaña a través de la División de Investigación y Extensión DIE, quienes de manera oportuna creyeron en la viabilidad de esta iniciativa, al grupo de investigación de la Facultad de Educación, Artes y Humanidades GIFEAH por defender y apoyar la ejecución de este proyecto de investigación que se convertiría a su vez en el primer proyecto de extensión de la facultad y que hoy reconoce los esfuerzos dados en el desarrollo de todas las actividades, finalmente a todos y cada uno de los participantes por su tiempo y dedicación, por supuesto a la oficina de Desarrollo Social de la Alcaldía Municipal de Ocaña.

\section{BIBLIOGRAFÍA}

BUENAVENTURA, N. (2001). La importancia de hablar mierda o los hilos invisibles del tejido social. Colombia: Magisterio.
CHIAVENATO, I. (2005). Comportamiento organizacional. La dinámica del éxito en las organizaciones. Australia: Thomson.

Constitución Política de la República de Colombia. (2010). Bogotá: Imprenta Nacional de Colombia.

CUNILL, N. (2007). Repensando lo público a través de la sociedad. . venezuela: Nueva Sociedad.

FONSECA YERENA, M. d. (2000). Comunicación Oral Fundamentos y Práctica Estratégica . Mexico: Pearson.

G., R. Á. (2005). Innovación y éxito en la gerencia cooperativa. Bogotá: Universidad Javeriana .

GUMUCIO DAGRÓN, A. (agosto 2004). El cuarto mosquetero: la comunicación para el cambio social. En: Investigación y desarrollo ISSN 0121-3261. Vol. $12, N^{\circ} 001$. Barranquilla, colombia.

HOPENHAYN, M. (2008). Inclusión y Exclusión Social en la Juventud Latinoamericana. Chile: En Pensamiento Iberoamericano.

M., T. C. (2005). Metodologia da pesquisa ação. . São Paulo: $14^{\mathrm{a}}$ ed.

Ocaña, A. M. (13 de marzo de 2015). http://www.implesof.com/tramlin/ja cl. 